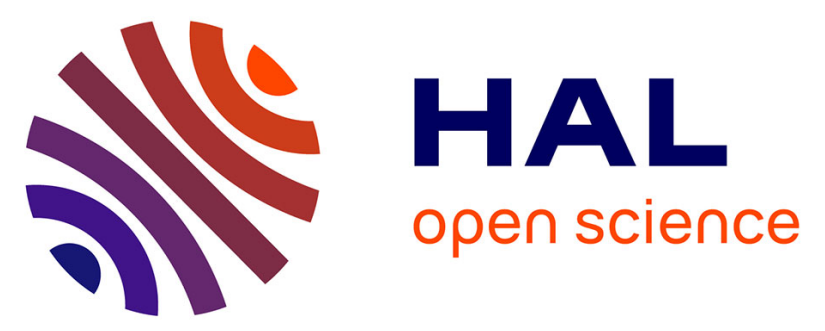

\title{
Long-term Kinetic Papilledema Improvement After Venous Sinus Stenting in Idiopathic Intracranial Hypertension.
}

Romain Touzé, Sophie Bonnin, Emmanuel Houdart, Patrick Nicholson, Bahram Bodaghi, Eimad Shotar, Frédéric Clarençon, Stéphanie Lenck, Valérie Touitou

\section{To cite this version:}

Romain Touzé, Sophie Bonnin, Emmanuel Houdart, Patrick Nicholson, Bahram Bodaghi, et al.. Longterm Kinetic Papilledema Improvement After Venous Sinus Stenting in Idiopathic Intracranial Hypertension.. Clinical Neuroradiology, In press, 10.1007/s00062-020-00908-z . hal-02880303

\section{HAL Id: hal-02880303 \\ https://hal.sorbonne-universite.fr/hal-02880303}

Submitted on 30 Jun 2020

HAL is a multi-disciplinary open access archive for the deposit and dissemination of scientific research documents, whether they are published or not. The documents may come from teaching and research institutions in France or abroad, or from public or private research centers.
L'archive ouverte pluridisciplinaire HAL, est destinée au dépôt et à la diffusion de documents scientifiques de niveau recherche, publiés ou non, émanant des établissements d'enseignement et de recherche français ou étrangers, des laboratoires publics ou privés. 


\section{Long-term kinetic papilledema improvement after venous sinus stenting in idiopathic intracranial hypertension}

Romain Touzé 1 , Sophie Bonnin 23 , Emmanuel Houdart 4, Patrick Nicholson 5, Bahram Bodaghi 26 , Eimad Shotar 7, Frédéric Clarençon 67 , Stéphanie Lenck 7, Valérie Touitou 26

\section{Affiliations}

1 Department of Ophthalmology, Pitié-Salpêtrière Hospital, APHP, 47, Bd de 1'Hôpital, 75013, Paris, France. r.touze.rt@gmail.com.

2 Department of Ophthalmology, Pitié-Salpêtrière Hospital, APHP, 47, Bd de l'Hôpital, 75013, Paris, France.

3 Department of Ophthalmology, Lariboisière Hospital, APHP, Paris, France.

4 Department of Neuroradiology, Lariboisière Hospital, APHP, Paris, France.

5 Joint Division of Medical Imaging, Department of Medical Imaging, UHN, University of Toronto, Toronto, Ontario, Canada.

$6 \quad$ Paris VI University, Sorbonne University, Paris, France.

7 Department of Neuroradiology, Pitié-Salpêtrière Hospital, APHP, Paris, France.

Search Terms: Idiopathic Intracranial Hypertension, All Neuro-ophthalmology, Optic nerve, MRI

Publication History: This manuscript was not previously published

Submission Type: Article

Title Character count: 89

Number of Tables: 2

Number of Figures: 2

Word count of Abstract: 249

Word count of Paper: 3208 


\begin{abstract}
:

\section{Background and Purpose}

The aim of this study was to assess the safety and effectiveness of lateral sinus stenosis (LSS) stenting in patients with idiopathic intracranial hypertension (IIH) who are refractory to medical treatment, particularly focusing on visual outcomes including papilledema.
\end{abstract}

\title{
Materials and Methods
}

Retrospective study of consecutive patients with IIH refractory to medical treatment who underwent LSS stenting. Clinical features, visual fields and optical coherence tomography (OCT) retinal nerve fiber layer (RNFL) and ganglion cell layer (GCL) thicknesses were assessed before stenting, at one month post-stenting and at last follow-up. Complications were also recorded.

\section{Results}

16 women were included, with a mean age of $39 \pm 11$ years. All patients had papilledema while $15 / 16(94 \%)$ had headaches. Mean visual acuity was $(0.036 \log$ MAR [ +0.4 to $+0.0 \log$ MAR] . RNFL thickness prior to stenting was $121.7 \mu \mathrm{m}( \pm 34.7)$ and mean GCL thickness was $80.2 \mu \mathrm{m}$ ( \pm 8.9 ). Mean follow-up was 19.7 months $( \pm 11.8)$. After stenting, acetazolamide was discontinued in 15/16 (94 \%) patients. Papilledema improved in 14/16 (88\%) of patients. The mean RNFL thickness was significantly decreased one month after stenting $(96.3 \pm 15.6 \mu \mathrm{m} ; \mathrm{p}$ $<0.001)$ and at last visit $(93.4 \pm 15.3 \mu \mathrm{m} ; \mathrm{p}<0.001)$. GCL thickness after LSS stenting was 
moderately decreased at the last visit examination: $80.2 \pm 8.9 \mu \mathrm{m}$ vs $78.0 \pm 10.7 \mu \mathrm{m} ;(\mathrm{p}<0.01)$. No stent-related complication occurred, while there was one case of restenosis.

\section{Conclusion}

Improvement of papilledema after LSS appears to occur relatively rapidly after the stenting. Our results further support the role of LSS in the treatment of IIH, especially with respect to visual symptoms. 


\section{Introduction}

One of the main symptoms of idiopathic intracranial hypertension (IIH) is papilledema [1]. IIH is diagnosed by use of the modified Dandy criteria. While lateral sinus stenoses (LSS) are diagnosed in more than $90 \%$ of the patients, their cause and pathophysiological role remain controversial $[2,3]$. Several studies have demonstrated the good safety and efficacy profiles of LSS stenting in these patients.

Patients suffering of IIH experience myriad symptoms which can have a significant effect on quality of life $[4,5]$, including headache, tinnitus and visual symptoms. The traditional firstline treatment for IIH patients includes weight-loss, medication (acetazolamide or topiramate as a second-line agent) or multiple lumbar puncture procedures.

In many centres, LSS stenting has replaced CSF diversion procedures for those patients who are refractory to medical management. However, the trajectory of improvement of papilledema after LSS stenting remains poorly known, and the place of this technique in the management of patients with rapid visual deterioration remains controversial. There remains relatively little published literature regarding the onset and magnitude of improvement in visual symptoms after LSS.

In addition to visual symptoms, vision changes in patients with IIH are generally assessed by using more quantifiable methods. High-definition optical coherence tomography (HD-OCT) allows acute assessment of retinal nerve fiber layer thickness (RNFL) and ganglion cell layer (GCL), which are objective and reproducible markers of severity of papilledema [6]. 
The purpose of this study is to use OCT parameters to assess the trajectory of improvement of papilledema after LSS stenting in patients with IIH refractory to medical therapy.

\section{Material and Methods}

\section{Patients}

We retrospectively collected clinical and radiological data of patients treated with LSS stenting for IIH in two tertiary eye-care centers (Pitié Salpêtrière Hospital, Paris, France and Lariboisière Hospital, Paris, France) between July 2015 and August 2017.

The inclusion criteria were:

- Patients treated by LSS stenting for IIH (as defined by the modified Dandy criteria) who were refractory to medical therapy as defined by:

- Worsening or no improvement of visual field defects and/or papilledema and/ or oculomotor nerve palsy despite maximal tolerated dosage of acetazolamide.

$\circ$ Recurrence of papilledema after tapering the dose of acetazolamide.

- Intolerance to acetazolamide with discontinuation of medical treatment.

- Disabling clinical signs (headaches, tinnitus...) despite medical treatment. 
- Patients with a lateral sinus trans-stenotic pressure gradient $>4 \mathrm{mmHg}$ (measured under local anesthesia) after discontinuation of the treatment with acetazolamide for at least 10 days before the procedure.

- Patients with an ophthalmological assessment performed in our institution at baseline and during follow-up.

The exclusion criteria were:

- Incomplete ophthalmological examination before or after LSS stenting.

- Patients with concomitant ophthalmic conditions, which could potentially confound assessment.

- Patients with fulminant IIH, defined as: [7]

$\bigcirc$ acute onset of symptoms and signs of intracranial hypertension;

- less than 4 weeks between onset of initial symptoms and severe visual loss;

$\bigcirc$ rapid worsening of visual loss over a few days

\section{Ophthalmic outcome}

Our primary outcome was the thickness of RNFL after the LSS stenting.

All patients had an ophthalmological examination before the stenting, at one month and every 6 months after stenting. All examinations were performed by an experienced senior ophthalmologist, and included visual field assessment, fundus examination, optical coherence tomography imaging and visual acuity (VA) assessment as measured by LogMAR (Minimum 
angle of resolution). The LogMAR is a visual acuity scale which has advantages over the more traditionally used Snellen charts, particularly when it comes to statistical analysis of the results. A score of zero indicates 'standard' or average visual acuity, with increasingly positive logarithmic scores indicating progressively poorer vision (1.3 representing blindness), and negative scores indicating better than average vision [8].

Retinal Nerve Fiber Layer (RNFL) and Ganglion cell layer (GCL) thicknesses were measured using a Cirrus high-definition Optical Coherence Tomography (HD-OCT) device. According to our institutional practice, OCT scanning was performed as follows: after pupil dilation, the optic disc cube was used to assess peripapillary RNFL thickness and the macular cube was used to assess GCL thickness. The GCL analysis algorithm was included in the Cirrus HDOCT 6.0 software. It detected and measured the macular Ganglion Cell-Inner Plexiform Layer (GCIPL) thickness within a $6 \times 6 \times 2$-mm elliptical annulus area centered on the fovea. The algorithm has been described previously in detail [9]. The GCL analysis also reported the minimum GCIPL thickness, which is the lowest GCIPL thickness over a single meridian crossing the annulus.

Visual fields (static or kinetic perimetry) were classified as 1) normal, 2) enlargement of the blind spot, 3) nasal or temporal defect, or 4) diffusely constricted [10]. This allowed classifying the clinical evolution of the visual field in worsened, stabilized or improved.

\section{Clinical outcomes}

The following clinical data were collected: age, gender, clinical symptoms of IIH (headache, pulsatile tinnitus, visual symptoms), Body Mass Index (BMI), CSF opening pressure, dose of 
acetazolamide before and after the procedure. All complications or side effects related to the procedure were also recorded.

\section{Radiological data}

All patients underwent a brain MRI to exclude tumors or vascular causes of intracranial hypertension. Radiological signs of intracranial hypertension (i.e empty sella, flattening of the posterior aspect of the globe, distension of perioptic subarachnoid space with or without a tortuous optic nerve) were also assessed. Venous sinus stenoses were evaluated with gadolinium-enhanced T1-weighted 3-dimensional gradient echo sequences and 3-dimensional gadolinium-enhanced venous angiography.

\section{Endovascular procedure}

The endovascular procedure was performed according to our institutional protocol which has been detailed previously [11]. Each patient underwent a digital subtraction angiography (DSA) with venous phases acquisitions to assess the venous anatomy. The trans-stenotic gradient was measured with patients under local anesthesia in order to avoid anaesthesiarelated fluctuations. Stenting was then performed with patients under general anesthesia [11]. Our protocol was already published in Lenck et al. [11]

The treatment by acetazolamide was discontinued once the endovascular procedure was performed. Patients were rapidly investigated after the procedure to assess the improvement with the discontinuation of acetazolamide.

\section{Follow up}


All patients were clinically assessed prior to the stenting, at one week then one month after the stenting and at 6 months intervals until stabilization. Once patients were stabilized from an ophthalmological point of view, the ophthalmological follow-up was then performed by the referring ophthalmologist.

\section{Data analysis}

Data analysis was performed using GraphPad Prism 5 (GraphPad Software, San Diego, CA, USA). Results were presented as means \pm standard deviations. Continuous data were analyzed using a Wilcoxon test, or the Mann-Whitney test, depending on the data distribution. The Fisher's exact test was used to compare qualitative data. Results were considered statistically significant when $\mathrm{p}$-value $<0.05$.

\section{Ethical statement}

This study has been approved by the local ethics committee (IRB 00008855). Because this study used data obtained as part of standard of care, the requirement for informed consent was waived.

\section{Data availability}

The authors declare that all data concerning this study are available on request.

\section{Results}


30 eyes from 16 patients were included; two eyes were excluded because of severe amblyopia. Clinical features at baseline are summarized in Table1.

Before stenting, all patients (100\%) had bilateral papilledema, 5/16 (31\%) had transient visual obscurations and 1/16 (6\%) had binocular diplopia caused by a sixth nerve palsy. 15/16(94\%) patients had headache, 13/16 (81\%) had pulsatile tinnitus. Mean best-corrected visual acuity (BCVA) was $0.036 \log \mathrm{MAR}[+0.4$ to $+0.0 \log \mathrm{MAR}]$ before stenting. Fourteen $(87.5 \%)$ patients had a normal BCVA and two (12.5\%) patients had an altered BCVA over 0.3 $\log$ MAR. Fifteen (94\%) patients were taking acetazolamide with a mean dosage of $660.7 \pm 270.5 \mathrm{mg} /$ day range $[250-2000 \mathrm{mg} /$ day]. Acetazolamide was not tolerated in one case. The median delay between the onset of IIH symptoms and stenting was 28.2 months $( \pm$ 21.4 months).

\section{Endovascular Treatment and Results}

Stenting of the right LS was performed in 11 patients, while the left LS was stented in 5 cases. The mean trans-stenotic gradient measured under local anesthesia before stenting was $13 \pm 6$ mmHg. A single stent was deployed in 15/16 (94\%) patients without complications. Acetazolamide was subsequently discontinued in 15/16 (94\%) patients. One patient had a de novo LS stenosis adjacent to the stent which occurred 3 months after stenting without symptom improvement. In this case, a subsequent stenting of this new stenosis was performed 8 months after the first procedure. Despite these stents, the patient failed to show improvement in symptoms and acetazolamide was required to control IIH symptoms and papilledema as well. However, their visual field defects continued to worsen. 


\section{Clinical Outcomes}

The mean follow-up of patients after stenting was $19.7( \pm 11.8)$ months. Complete resolution of headaches was noted in $8 / 15(53 \%)$ patients, while they improve in $5 / 15(33 \%)$ patients. Headaches were unchanged in 2/15 (13\%) patients. Pulsatile tinnitus resolved immediately after stent placement in $12 / 13(92 \%)$ patients.

At one-month follow-up, papilledema was completely resolved in 14/16 (87.5\%) patients and remained unchanged in 2/16 (12.5\%). At most recent follow-up, papilledema had resolved in $15 / 16(93.8 \%)$ patients and remained unchanged in one $1 / 16(6.2 \%)$.

Concerning our primary outcome, the mean RNFL thickness at initial presentation was 121.7 $\pm 34.7 \mu \mathrm{m}$. This had significantly decreased at one-month follow-up $(96.3 \pm 15.6 \mu \mathrm{m}, \mathrm{p}<$ 0.001) and further decreased at most recent follow up $(93.4 \pm 15.3 \mu \mathrm{m}, \mathrm{p}<0.001)$ Fig 1.

GCL thickness decreased significantly from $80.2 \pm 8.9 \mu \mathrm{m}$ before stenting to $79.8 \pm 9.5 \mu \mathrm{m}$ one month after stenting $(\mathrm{p}=0.23)$ and $78.0 \pm 10.7 \mu \mathrm{m}$ at last follow-up $(\mathrm{p}<0.01)$ Fig2.

All results are summarized in Table 2.

Visual fields improved in 16/30 (53.3\%) patients at last follow-up, while it remained stable in 13/30 (43.3\%) patients and was worsened in one case Table 2.

\section{Discussion}


Our study demonstrated a significant improvement in visual parameters after LSS stenting for IIH, including papilledema recovery and decrease in RNFL thickness. Of note, this decrease in RFNL thickness was seen as quickly as one month after stenting.

Stenting of LSS was first reported as a potential treatment for IIH in 2002 by Higgins et al [12]. There has been increasing interest in this technique, with many groups reporting their favourable experience, demonstrating the excellent safety profile and efficacy of this technique [11-17]. In a recent meta-analysis, Nicholson et al [18] reported an overall rate of improvement in papilledema in $93.7 \%$ of patients, an overall rate of improvement or resolution of headache in $79.6 \%$ and resolution in pulsatile tinnitus in $90.3 \%$ of patients. The rate of major complications was $1.9 \%$ without long-term morbidity or mortality, while the overall rate of recurrence of IIH symptoms was $9.8 \%$. Based on these results, LSS stenting has in many centers progressively replaced CSF diversion procedures as a first-line treatment for those carefully selected patients with IIH refractory to medical therapy. However, there is relatively little evidence regarding the degree of improvement of visual parameters as well as their chronological evolution after LSS.

As for visual outcomes, we found only 4 previous studies looking at RNFL thickness following stenting of LSS in IIH [17,19-21]. The IIHTT study [6] showed that in patients with newly diagnosed IIH, RNFL was strongly correlated with Frisen grade (a grading system which allowed us to grade and track papilledema) [22]. In our study, each patient had OCT measurements including RNFL and GCL, both preceding the stenting and during follow-up visits. The improvement of RNFL thickness after stenting was statistically significant (121.7 $\mu \mathrm{m}$ vs $93.4 \mu \mathrm{m}$ ) with $\mathrm{p}<0.001$, occurred relatively early (with significant changes seen at one-month follow-up), and was sustained throughout the follow-up period (mean follow-up: 
19.7 months). There are however several limitations with measuring RNFL thickness in these cases, such as with the combination of atrophy and papilledema, which could be falsely reassuring. The assessment of RNFL thickness must therefore be performed in conjunction with clinical findings as well as other parameters such as GCL. Indeed, in cases of optic nerve atrophy the GCL can be decreased and abnormal. To our knowledge, we are the first group to study the GCL thickness after stenting of LSS in IIH. The GCL thickness is used to monitor the loss of ganglion cell layer in case of glaucoma or optic neuropathy. The GCL thickness is a valuable tool to distinguish an optic nerve injury in case of optic nerve swelling. In case of IIH, the GCL thinning could reflect an early optic nerve injury, while the RNFL can be falsely normal or increased due to optic nerve swelling [6]. We reported a mean GCL thickness of $80.2 \mu \mathrm{m}$ before stenting and $78.0 \mu \mathrm{m}$ after stenting (19.7 months). This difference is slight, but within the normal range of GCL thickness. We can therefore infer that our patients had no clinically significant optic nerve atrophy. Therefore, in this study, we can only postulate that changes sustained as a result of intracranial hypertension were not sufficient to induce a significant optic neuropathy. Few studies have looked at GCL thickness in IIH overall - the conclusions of the NORDIC Idiopathic Hypertension Study Group were that GCL thickness was in the normal range in $93 \%$ [6]. It appeared to be difficult to find evidence of early axonal and retinal ganglion cell damage in IIH using OCT. The same conclusion has been reached in patients with non-arteritic anterior ischemic optic neuropathy (NAION) or optic neuritis [23]. This is in accordance with our findings. One group monitored GCL thickness in IIH [24], and they did not found any significant alterations in GCL thickness during a mean follow-up of less than ten months. In our study, we found a slight but definite modification of GCL thickness during a longer duration follow-up. To our knowledge, we are the first to assess the long-term changes of GCL thickness in patients with 
IIH treated by LSS stenting. In the future, prospective collection of GCL thickness data in larger populations of IIH patients will be needed to further understand how this parameter changes in these patients, and perhaps to integrate that into our clinical practice.

Among patients with IIH, 25\% may have permanent visual defects which can ultimately lead to blindness [25], and so it is desirable that any treatment effect on visual field outcomes occurs as quickly as possible. The maximal improvement in visual symptoms in the NORDIC trial was not seen until 6 months after initiation of medication [26]. Indeed, one major point of our study was the early benefit of stenting with regards to papilledema. We observed a significant improvement in papilledema as early as one month after the procedure. This information points to the real and early efficacy of stenting in this respect. It could have relevance in the treatment of patients with fulminant IIH [17]. We also know that compliance with medical therapy in IIH patients can be challenging - in one study looking at tolerability in this patient cohort, only $44.1 \%$ of patients were able to tolerate the maximum dose of acetazolamide [27]. Shazly et al have demonstrated that venous sinus stenting significantly shortens the duration of medical therapy, improving visual prognosis [21].

In the NORDIC trial, [27] the mean dosage of acetazolamide was $2500 \mathrm{mg} / \mathrm{day}$. This was a significantly higher dosage than the mean doses used in our patient cohort. However, when compared to the NORDIC trial, our patients appeared to be less severe in terms of BMI, CSF pressure, visual acuity or visual field deficits. In addition, in clinical practice we find that these higher doses are often not tolerated by patients due to side effects.

One other important point from our study was the significant delay between onset of IIH symptoms and stenting (28.2 months). Despite this delay, papilledema still significantly 
improved with stenting. This supports the concept of relatively rapid reversibility of papilledema after LSS stenting even in long standing IIH without optic nerve atrophy.

The rate of recurrence of $\mathrm{IIH}$ following stent placement is around $10 \%$, supporting the need for long-term ophthalmological follow-up in those patients $[16,18,28]$. The recurrence of IIH is, in many cases, associated with stent-adjacent stenosis (SAS), i.e. a recurrent area of stenosis in the lateral sinus which occurs adjacent to the initial stent. A second stenting allows the resolution of symptoms of IIH in most cases. Factors which have been associated with recurrence of IIH after stenting include extrinsic stenoses, younger patients and higher CSF opening pressure [29]. Some technical points may allow us to decrease the incidence of this recurrence of IIH after stenting, such as implanting longer (or multiple) stents in young patients with extrinsic stenoses to cover the transverse sinus from the torcula to the sigmoid sinus [11]. Even these technical considerations may not allow us to completely prevent IIH recurrences following stenting. Thus, continued clinical and ophthalmological follow-up is warranted.

\section{Limitations}

The main limitation of our study is of course the small patient cohort and its retrospective design. A single prospective study has been published so far, albeit with a short follow-up of the patients [17]. Because of the relatively recent development of this stenting technique, the lack of long-term follow-up clinical data remains one of the main limitations common to all studies of LSS stenting in selected patients with IIH. 
Our population is not entirely concordant with other those of other groups who treated IIH patients with LSS. Indeed, we have generally not treated patients with fulminant IIH by venous stenting. Our population also seems to have less severe IIH than in other previously published series since the RFNL thickness is lower than in other papers $[29,30]$. Eleven $(36 \%)$ of the eyes included in our study had a normal visual field examination before stenting [10], explaining why the improvement of the visual field seems to be less pronounced in our series than in other published studies $[17,21,30]$. In our population, $94 \%$ of patients experienced disabling headaches despite medical therapy. These patients were selected for a stenting procedure by a multidisciplinary discussion between the neurologist, interventional neuroradiologist and ophthalmologist. In this respect, we did not offer stenting for visual symptoms or findings alone. This could also help explain why our population appeared atypical concerning visual findings pre-stenting. Despite these differences, we feel that our results were still relevant with regards to papilledema improvement.

We had a mean follow-up period of 19.7 months. This was relatively long when compared to some previously published cohorts. As outlined in our methods, once patients were stabilized from an ophthalmological point-of-view we stopped following them centrally at our tertiary centre. Patients were referred back if they disimproved. It is therefore likely that most of our cohort had sustained improvement in symptoms following stenting.

\section{Conclusion}

According to our results, patients with medically refractory IIH papilledema experienced significant improvements in RNFL thickness as early as one month after LSS stenting. Improvement in visual parameters was sustained over time without recurrence of clinical 
symptoms, and the procedure was associated with no significant complications. Sinus stenting was well tolerated, and was associated with rapid and sustained improvements in both qualitative and quantitative measures of visual outcome. Our study supports the concept of early reversibility of papilledema after LSS stenting in most patients with long-standing IIH. Furthermore, most of our patients (94\%) were able to discontinue acetazolamide following the procedure. While larger prospective comparative studies are still needed to assess the place of LSS stenting in IIH, our results point to the usefulness of this technique in the specific treatment of visual symptoms and papilledema. 


\section{Reference}

1. Raoof N, Sharrack B, Pepper IM, Hickman SJ. The incidence and prevalence of idiopathic intracranial hypertension in Sheffield, UK: Epidemiology of IIH. Eur J Neurol.

2011;18:1266-8.

2. Farb RI, Vanek I, Scott JN, Mikulis DJ, Willinsky RA, Tomlinson G, et al. Idiopathic intracranial hypertension The prevalence and morphology of sinovenous stenosis. Neurology. 2003;60:1418-24.

3. Lenck S, Radovanovic I, Nicholson P, Hodaie M, Krings T, Mendes-Pereira V. Idiopathic intracranial hypertension: The veno glymphatic connections. Neurology. 2018;91:515-22.

4. Digre KB, Bruce BB, McDermott MP, Galetta KM, Balcer LJ, Wall M. Quality of life in idiopathic intracranial hypertension at diagnosis. Neurology. 2015;84:2449-56.

5. Mulla Y, Markey KA, Woolley RL, Patel S, Mollan SP, Sinclair AJ. Headache determines quality of life in idiopathic intracranial hypertension. J Headache Pain [Internet]. 2015;16. Available from: https://www.ncbi.nlm.nih.gov/pmc/articles/PMC4436432/

6. OCT Sub-Study Committee for NORDIC Idiopathic Intracranial Hypertension Study Group, Auinger P, Durbin M, Feldon S, Garvin M, Kardon R, et al. Baseline OCT measurements in the idiopathic intracranial hypertension treatment trial, part II: correlations and relationship to clinical features. Invest Ophthalmol Vis Sci. 2014;55:8173-9.

7. Thambisetty M, Lavin PJ, Newman NJ, Biousse V. Fulminant idiopathic intracranial hypertension. Neurology. 2007;68:229-32.

8. Bailey IL, Lovie-Kitchin JE. Visual acuity testing. From the laboratory to the clinic. Vision Res. 2013;90:2-9. 
9. Mwanza J-C, Budenz DL. New developments in optical coherence tomography imaging for glaucoma: Curr Opin Ophthalmol. 2017;1.

10. Bruce BB, Kedar S, Van Stavern GP, Monaghan D, Acierno MD, Braswell RA, et al. Idiopathic intracranial hypertension in men. Neurology. 2009;72:304-309.

11. Lenck S, Vallée F, Labeyrie M-A, Touitou V, Saint-Maurice J-P, Guillonnet A, et al. Stenting of the Lateral Sinus in Idiopathic Intracranial Hypertension According to the Type of Stenosis: Neurosurgery. 2016;1.

12. Higgins JNP, Owler BK, Cousins C, Pickard JD. Venous sinus stenting for refractory benign intracranial hypertension. The Lancet. 2002;359:228-30.

13. Aguilar-Pérez M, Martinez-Moreno R, Kurre W, Wendl C, Bäzner H, Ganslandt O, et al. Endovascular treatment of idiopathic intracranial hypertension: retrospective analysis of immediate and long-term results in 51 patients. Neuroradiology. 2017;59:277-87.

14. Kumpe DA, Seinfeld J, Huang X, Mei Q, Case DE, Roark CD, et al. Dural sinus stenting for idiopathic intracranial hypertension: factors associated with hemodynamic failure and management with extended stenting. J NeuroInterventional Surg.

2016;neurintsurg-2016-012810.

15. Zhou D, Meng R, Zhang X, Guo L, Li S, Wu W, et al. Intracranial hypertension induced by internal jugular vein stenosis can be resolved by stenting. Eur J Neurol. 2018;25:365-e13.

16. Starke RM, Wang T, Ding D, Durst CR, Crowley RW, Chalouhi N, et al. Endovascular Treatment of Venous Sinus Stenosis in Idiopathic Intracranial Hypertension: Complications, Neurological Outcomes, and Radiographic Results. Sci World J [Internet]. 2015;2015.

Available from: https://www.ncbi.nlm.nih.gov/pmc/articles/PMC4471318/

17. Dinkin MJ, Patsalides A. Venous Sinus Stenting in Idiopathic Intracranial Hypertension: Results of a Prospective Trial. J Neuro-Ophthalmol Off J North Am Neuro-Ophthalmol Soc. 2017;37:113-21.

18. Nicholson P, Brinjikji W, Radovanovic, Hilditch CA, Tsang ACO, Krings T, et al. Venous sinus stenting for idiopathic intracranial hypertension: a systematic review and meta-analysis. J Neurointerventional Surg. 2018;

19. Liu KC, Starke RM, Durst CR, Wang TR, Ding D, Crowley RW, et al. Venous sinus stenting for reduction of intracranial pressure in IIH: a prospective pilot study. J Neurosurg. 2017;127:1126-33.

20. Alessi G, Levrier O, Conrath J, Hoffart L, Donnet A, L'attention L, et al. [Optical coherence tomography in following up papilledema in idiopathic intracranial hypertension treated with lateral sinus stent placement]. J Fr Ophtalmol. 2010;33:637-48.

21. Shazly TA, Jadhav AP, Aghaebrahim A, Ducruet AF, Jankowitz BT, Jovin TG, et al. Venous sinus stenting shortens the duration of medical therapy for increased intracranial pressure secondary to venous sinus stenosis. J Neurointerventional Surg. 2018;10:310-4. 
22. Frisen L. Swelling of the optic nerve head: a staging scheme. J Neurol Neurosurg Psychiatry. 1982;45:13-8.

23. Fard MA, Ghahvechian H, Sahrayan A, Subramanian PS. Early Macular Vessel Density Loss in Acute Ischemic Optic Neuropathy Compared to Papilledema: Implications for Pathogenesis. Transl Vis Sci Technol [Internet]. 2018;7. Available from: https:// www.ncbi.nlm.nih.gov/pmc/articles/PMC6159734/

24. Albrecht P, Blasberg C, Ringelstein M, Müller A-K, Finis D, Guthoff R, et al. Optical coherence tomography for the diagnosis and monitoring of idiopathic intracranial hypertension. J Neurol. 2017;264:1370-80.

25. Wall M, GEORGE D. Idiopathic intracranial hypertension: a prospective study of 50 patients. Brain. 1991;114:155-180.

26. NORDIC Idiopathic Intracranial Hypertension Study Group Writing Committee, Wall M, McDermott MP, Kieburtz KD, Corbett JJ, Feldon SE, et al. Effect of acetazolamide on visual function in patients with idiopathic intracranial hypertension and mild visual loss: the idiopathic intracranial hypertension treatment trial. JAMA. 2014;311:1641-51.

27. Ten Hove MW, Friedman DI, Patel AD, Irrcher I, Wall M, McDermott MP, et al. Safety and Tolerability of Acetazolamide in the Idiopathic Intracranial Hypertension Treatment Trial. J Neuro-Ophthalmol Off J North Am Neuro-Ophthalmol Soc. 2016;36:13-9.

28. Satti SR, Leishangthem L, Chaudry MI. Meta-Analysis of CSF Diversion Procedures and Dural Venous Sinus Stenting in the Setting of Medically Refractory Idiopathic Intracranial Hypertension. Am J Neuroradiol. 2015;36:1899-904.

29. Dinkin MJ, Patsalides A. Venous Sinus Stenting for Idiopathic Intracranial Hypertension: Where Are We Now? Neurol Clin. 2017;35:59-81.

30. Smith KA, Peterson JC, Arnold PM, Camarata PJ, Whittaker TJ, Abraham MG. A case series of dural venous sinus stenting in idiopathic intracranial hypertension: association of outcomes with optical coherence tomography. Int J Neurosci. 2017;127:145-53. 


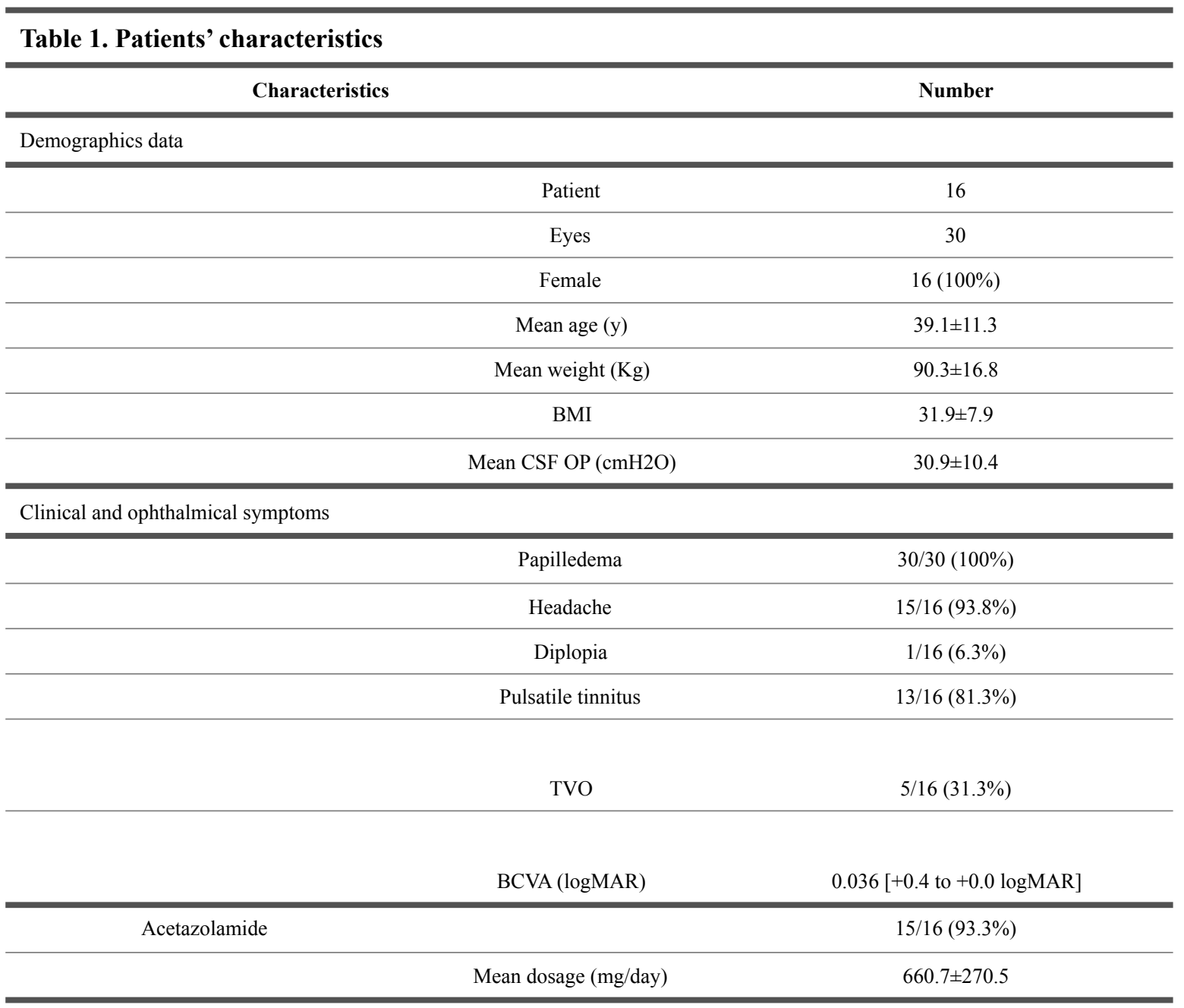

Table 1. Summarized of patient's characteristics before stenting

BMI, Body Mass Index; BCVA, Best Correct Visual Acuity; CSF OP, CerebroSpinal Fluid Opening Pressure; LogMAR, Logarithm of the Minimum Angle of Resolution; TVO, Transient Visual Obscurations 


\section{Table 2 Results}

\begin{tabular}{|c|c|c|c|c|c|}
\hline Outcome & Before Stenting & 1 month after Stenting & $\mathbf{p}$ & $\begin{array}{c}\text { Final follow-up } \\
\text { after Stenting }\end{array}$ & $\mathbf{p}$ \\
\hline Headache & $15 / 16$ & $6 / 16$ & 0.16 & $2 / 16$ & $<0.001$ \\
\hline Tinnitus & $13 / 16$ & $1 / 16$ & $<0.001$ & $1 / 16$ & $<0.001$ \\
\hline Diplopia & $1 / 16$ & $1 / 16$ & 1 & $1 / 16$ & 1 \\
\hline BCVA & $\begin{array}{c}0.036[+0.4 \text { to }+0.0 \\
\operatorname{logMAR}]\end{array}$ & $\begin{array}{c}0.036[+0.4 \text { to }+0.0 \\
\operatorname{logMAR}]\end{array}$ & 1 & $\begin{array}{c}0.032[+0.4 \text { to }+0.0 \\
\text { logMAR }]\end{array}$ & 0.59 \\
\hline Papilledema & $16 / 16$ & $1 / 16$ & $<0.001$ & $2 / 16$ & $<0.001$ \\
\hline Mean OCT RNFL & $121.7[73$ to 204$] \mu \mathrm{m}$ & $96.2[71$ to 139$] \mu \mathrm{m}$ & $<0.001$ & $93.4[77$ to 142$] \mu \mathrm{m}$ & $<0.001$ \\
\hline Mean OCT GCL & $80.2[69$ to 90$] \mu \mathrm{m}$ & 79.8 [74 to 90$] \mu \mathrm{m}$ & 0.23 & $78.0[59$ to 90$] \mu \mathrm{m}$ & $<0.01$ \\
\hline \multicolumn{6}{|l|}{ Visual Fields results } \\
\hline \multicolumn{6}{|l|}{ Scale } \\
\hline 1 & $11 / 30$ & ND & & $18 / 30$ & 0.12 \\
\hline 2 & $10 / 30$ & ND & & $5 / 30$ & 0.23 \\
\hline 3 & $5 / 30$ & ND & & $4 / 30$ & 1 \\
\hline 4 & $4 / 30$ & ND & & $3 / 30$ & 1 \\
\hline
\end{tabular}

Table 2. Summarized of results one month after the stenting and at the last follow-up

BCVA, Best Correct Visual Acuity; GCL, Ganglion Cell Layer; OCT, Optical Coherence Tomography; RNFL, Retinal Nerve Fiber Layer.

Results concerning visual fields assessment.

1) normal; 2) enlargement of the blind spot;3) nasal or temporal defect; 4) diffusely constricted 


\section{TABLES LEGENDS}

\section{Table 1 Patients' characteristics}

Summarized of patient's characteristics before stenting

BMI, Body Mass Index; BCVA, Best Correct Visual Acuity; CSF OP, CerebroSpinal Fluid Opening Pressure; LogMAR, Logarithm of the Minimum Angle of Resolution; TVO, Transient Visual Obscurations

\section{Table 2 Results}

Summarized of results one month after the stenting and at the last follow-up

BCVA, Best Correct Visual Acuity; GCL, Ganglion Cell Layer; OCT, Optical Coherence Tomography; RNFL, Retinal Nerve Fiber Layer.

Results concerning visual fields assessment. 
1) normal; 2) enlargement of the blind spot;3) nasal or temporal defect; 4) diffusely constricted

\section{FIGURES LEGENDS}

Figure 1 Retinal Nerve Fiber Layer (RNFL) thickness changes over time

Dot plots of the before stenting values, the first follow-up one month after the stenting and the last visit as well as $\mathrm{p}$ values for their comparison. Horizontal lines are median and the interquartile range. Each cross represents one patient.

RNFL were significantly reduced as soon as the first month after the stenting $(p<0.0001)$ and at the last visit $(\mathrm{p}<0.0001)$

RNFL, Retinal Nerve Fiber Layer; M1, One month after

Figure 2 Ganglion Cell Layer (GCL) thickness changes over time 
Dot plots of the before stenting values, the first follow-up one month after the stenting and the last visit as well as $\mathrm{p}$ values for their comparison. Horizontal lines are median and the interquartile range. Each dot represents one patient.

GCL were not significantly reduced at the first month after the stenting $(p=0.23)$ and at the last visit $(\mathrm{p}<0.01)$

M1, One month after 